\title{
Effect of various techniques of Anesthesia in elective Caesarian section on short term Neonatal outcome
}

\author{
Kosam D ${ }^{1}$, Kosam A², Murthy $\mathbf{M}^{3}$ \\ ${ }^{1}$ Dr Durga Kosam, Assistant Professor, Department of Anesthesia and Critical Care, ${ }^{2}$ Dr Ajay Kosam, Associate Professor, \\ Department of Pediatrics, ${ }^{3}$ Dr M Madhumita Murthy, Associate Professor \& Head, Department of Anesthesia and Critical \\ Care Chhattisgarh Institute of Medical Sciences, Bilaspur, CG, India.
}

Address for correspondence: Dr Ajay Kosam, E mail: kosamajay@gmail.com

\begin{abstract}
Introduction: The basic aim of obstetric anesthesia is to provide adequate maternal pain relief with no deleterious effect on mother and newborn. This study aimed to assess the effect of spinal anesthesia, epidural anesthesia and general anesthesia using thiopentone sodium as induction agent on neonates delivered after elective caesarian section. Materials and Methods: This is a prospective descriptive study at a tertiary care teaching hospital from June 2013 to May 2014 . 60 cases of elective caesarian section admitted in Department of Obstetrics and Gynecology were studied. Patients were randomly divided into 3 groups each of 20 cases. Group 1 received spinal anesthesia, group 2 epidural anesthesia and group 3 general anesthesia. Neonatal outcome was assessed in relation to anesthetic techniques used. Results: The mean Apgar score at 1 min was lower in GA group $(7+/-1.025)$ than in spinal anesthesia group $(8.1+/-0.78)$ and epidural anesthesia group (8.35 $+/-0.745)$. Total 3/60 (5\%) neonates required resuscitation at birth all of which were in GA group. Induction delivery interval of $<5$ min and $>20$ min was associated with need for resuscitation at birth. Moderate depression of neonates (1 min Apgar score of 4-6) was observed in 2/20 (10\%) neonates in group 3. Conclusion: Neonates born by elective LSCS under GA have lower 1 min Apgar scores. Induction delivery interval of $<5$ min and $>20$ min is associated with need for resuscitation at birth in neonates in GA group. These effects can be minimized by maintaining the ID interval between 5 15 minutes.
\end{abstract}

Key words: Anesthesia, Apgar Score, Induction- Delivery Interval, Neonate.

\section{Introduction}

The choice of anesthesia for cesarean section depends upon indication for operation, its urgency, patients and obstetrician preferences and anesthesiologist. Either of the general, spinal anesthesia and epidural anesthesia is not ideal for cesarean section because each has advantages and risk to both mother and fetus. However the aim of anesthetist is to choose the method which is safest and most comfortable for the mother, least depressant to the newborn and which provides optimal working conditions for the obstetrician [1]. The outcome of anesthesia either spinal or general depends upon the condition of the mother and more importantly effects on newborn. APGAR score is the best parameter to assess the immediate condition of the baby. Over the past few decades, there has been a tremendous increase in the number of deliveries performed by cesarean section in most industrialized countries. In the

Manuscript received: $24^{\text {th }}$ Aug 2014

Reviewed: $08^{\text {th }}$ Sept 2014

Author Corrected: $24^{\text {th }}$ Sept 2014

Accepted for Publication: $4^{\text {th }}$ Oct 2014
US the overall cesarean section rates increased by $14 \%$ from 1998 to 2001 as a result of a $13 \%$ increase in medically indicated primary cesarean section and a 53\% increase in the rate of elective primary caesarian section [2]. Because of this global increase in cesarean section rates, more attention is being paid to their outcomes. The effect of type of anesthesia on neonates is less clear, with some studies showing no difference in neonatal outcome between the two groups and others maintaining that neonatal outcome are better with regional anesthesia than with GA. In a recent extensive review, Afolabi et al [3] concluded that "there was no evidence from the review to show that regional anesthesia is superior to GA in terms of major maternal or neonatal outcomes".

The purpose of the present study was to determine the effect of regional and general anaesthesia in elective cesarean section on neonatal outcome in terms of need for resuscitation at birth, Apgar scores and neurobehavioral score. 


\section{Material and Methods}

This study was carried out at Chhattisgarh Institute of Medical Sciences hospital Bilaspur from June 2013 to May 2014. This study was performed on 60 healthy full term patients presenting for elective lower segment cesarean section.

Pregnant women with a diagnosis of preeclampsia or eclampsia, with heart disease or taking any chronic medications other than prenatal vitamins, fetal distress, previous exhaustive labor, underlying medical conditions like diabetes mellitus or considered to have high-risk pregnancies were excluded.

Patients were randomly divided into 3 groups each of 20 cases according to the anaesthetic technique used using sealed envelopes which were opened by the anesthesiologist before the surgery. In group 1 LSCS was performed under spinal anesthesia, group 2 received epidural anaesthesia and group 3 patients were induced with general anaesthesia using thiopentone sodium as induction agent. The groups were similar in regard to age, weight and height variables. Indications for cesarean section were previous LSCS, cephalopelvic disproportion, abnormal presentation, post maturity and rupture of membranes for more than 24 hours. Total 60 patients were included and a written consent was taken from each patient.

\section{Method for General Anaesthesia}

An infusion of RL was started in all patients prior to induction of anesthesia. Patients were preoxygenated with $100 \%$ oxygen for $3 \mathrm{~min}$. followed by induction with 4-5 $\mathrm{mg} / \mathrm{kg}$ thiopental and $2 \mathrm{mg} / \mathrm{kg}$ succinylcholine. Oxygenation was continued till full effect of Sch appeared.

Trachea was intubated with cuffed tube. No volatile anaesthetic agent was given prior to delivery of baby. Analgesia was maintained with oxygen and nitrous oxide. In some cases Atracurium was given prior to delivery of infant.

\section{Method for Spinal Anesthesia}

Patient was preloaded with $1000 \mathrm{ml}$ of RL solution. Patient was placed in lateral position and space between 3rd and 4th lumbar spine was identified and marked. After taking all aseptic measure lumbar puncture was done with 24 - 25 gauge pencil point spinal needle and hyperbaric Bupivacaine $0.5 \%, 2.2-2.5 \mathrm{ml}$ was administered .Immediately after injection of Bupivacaine patient was placed in supine position.

\section{Method of Epidural Anaesthesia}

All EA patients were prehydrated with $500 \mathrm{~mL}$ lactated Ringer's solution before induction of anesthesia. EA was performed with the patient in the lateral position at the L2-3 or L3-4 intervertebral space using a midline approach by loss of resistance to saline. The catheter was introduced 3 to $4 \mathrm{~cm}$ beyond the tip of the Tuohy needle in all patients. The needle was then removed, the catheter secured to the skin, and the patient placed in the supine position with left uterine displacement. Then, $12 \mathrm{~mL}$ $0.5 \%$ Bupivacaine without epinephrine was injected after a test dose. Additional 4-mL doses of Bupivacaine were injected into the catheter until a bilateral $\mathrm{T} 4$ block (pinprick) was established. CS was started soon after an adequate epidural block was established.

Monitoring was done for the pulse, N.I.B.P., oxygen saturation, ECG and urinary output. During every cesarean section under general or regional anaesthesia time of induction, time of incision to skin, time of incision of the uterus and time of delivery of baby was recorded.

All neonates were assessed immediately after birth by a pediatrician to determine the need for resuscitation. Neonatal resuscitation was performed by a pediatrician as per American Academy of Pediatrics and American Heart Association's International Guidelines for emergency cardiovascular care of newborn [4].

\section{Recording of Apgar score}

In this study Apgar score of all 60 neonates were recorded by a Pediatrician. Apgar scores were recorded at 1 minute and 5 minutes after delivery. Birth weight of every baby was recorded.

\begin{tabular}{|l|l|l|l|}
\hline \multicolumn{4}{|c|}{ Apgar score } \\
\hline Sign & 0 & 1 & 2 \\
\hline Heart rate & Absent & $<100 /$ min & $>100 /$ min \\
\hline $\begin{array}{l}\text { Respiratory } \\
\text { effort }\end{array}$ & Absent & $\begin{array}{l}\text { Weak cry, } \\
\text { hypoventilation }\end{array}$ & $\begin{array}{l}\text { Good strong } \\
\text { cry }\end{array}$ \\
\hline Muscle tone & Limp & $\begin{array}{l}\text { Some flexion of } \\
\text { extremities }\end{array}$ & $\begin{array}{l}\text { Well flexed, } \\
\text { active motion }\end{array}$ \\
\hline Colour & $\begin{array}{l}\text { Blue or } \\
\text { pale }\end{array}$ & $\begin{array}{l}\text { Body pink with } \\
\text { blue extremities }\end{array}$ & $\begin{array}{l}\text { Completely } \\
\text { pink }\end{array}$ \\
\hline $\begin{array}{l}\text { Reflex } \\
\text { irritability }\end{array}$ & $\begin{array}{l}\text { No } \\
\text { response }\end{array}$ & Grimace & Cough/sneeze \\
\hline
\end{tabular}

\section{Neurobehavioral assessment of newborn}

Neurobehavioral assessment of newborn was done by Scanlon early neonatal neurobehavioral scale [5] which includes- 
Test for muscle tone:

1. Pull to sit

2. Arm recoil

3. Truncal tone

4. General body tone

Test for primitive reflexes:

1. Rooting reflex.

2. Sucking reflex.

3. Moro reflex

4. Placing reflex.
Test for response to external stimuli:

1. Pinprick.

2. Sound

3. Alertness

Scoring was done as -

$0=$ absent response.

$1=$ weak/delayed response.

$2=$ Normal response

$3=$ Strong response.

\section{Results}

Pie chart 1: Indications of Cesarean section

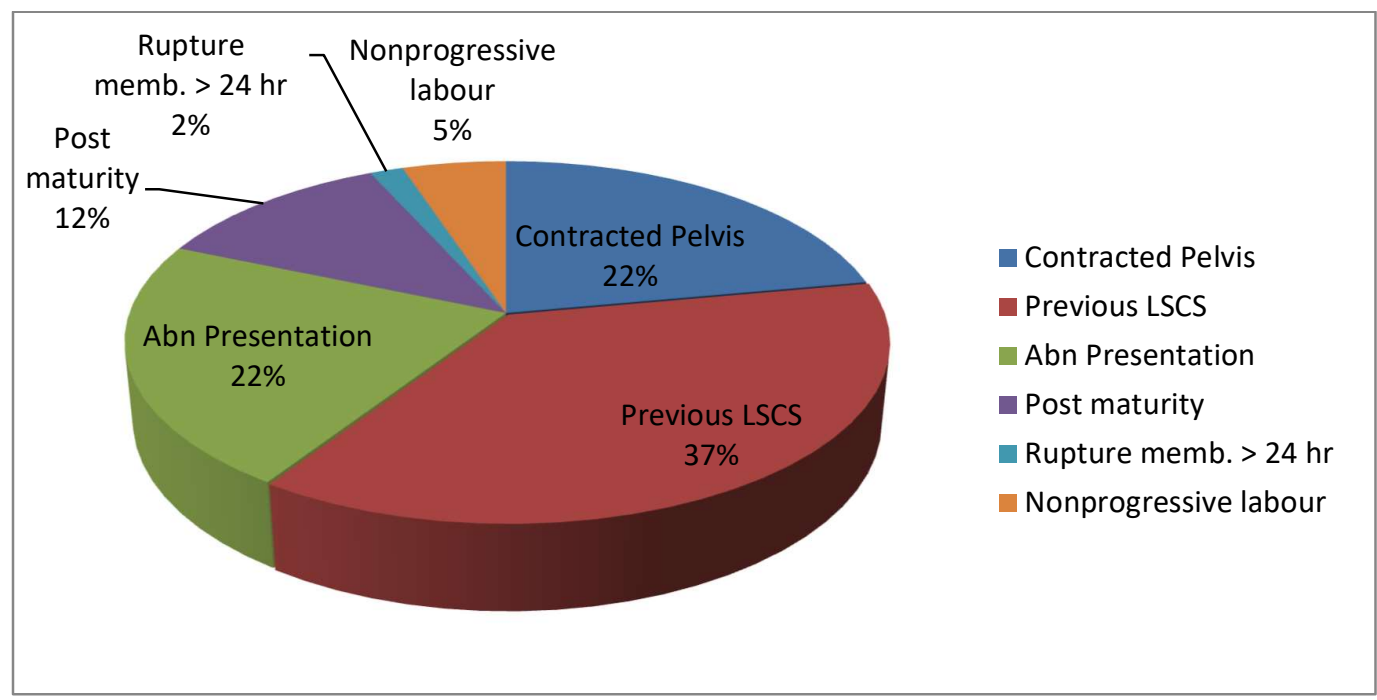

Most common indication for elective LSCS was previous LSCS (37\%) followed by contracted pelvis and abnormal presentation $(22 \%)$ and post maturity $(12 \%)$.

Table 1: Apgar scores at $1 \mathrm{~min}$ and $5 \mathrm{~min}$ intervals in group 1(SA), group 2(EA) and group 3(GA).

\begin{tabular}{|l|l|c|c|c|c|c|}
\hline \multirow{2}{*}{$\begin{array}{l}\text { Apgar } \\
\text { Score }\end{array}$} & \multicolumn{3}{|c|}{ At 1 minute } & \multicolumn{3}{c|}{ At 5 minute } \\
\cline { 2 - 7 } & $\begin{array}{l}\text { SA group } \\
\mathbf{n = 2 0}\end{array}$ & $\begin{array}{c}\text { EA group } \\
\mathbf{n = 2 0}\end{array}$ & $\begin{array}{c}\text { GA group } \\
\mathbf{n = 2 0}\end{array}$ & $\begin{array}{c}\text { SA group } \\
\mathbf{n}=\mathbf{2 0}\end{array}$ & $\begin{array}{c}\text { EA group } \\
\mathbf{n}=\mathbf{2 0}\end{array}$ & $\begin{array}{c}\text { GA group } \\
\mathbf{n}=\mathbf{2 0}\end{array}$ \\
\hline$\geq 7$ & 20 & 20 & 17 & 20 & 20 & 20 \\
\hline$\leq 6$ & 0 & 0 & 3 & 0 & 0 & 0 \\
\hline
\end{tabular}

The mean Apgar score at 1 minute was $8.1 \pm 0.78,8.35 \pm 0.745$ and $7.0 \pm 1.025$ in group 1, group 2 and group 3 respectively. All neonates delivered by elective LSCS under spinal anesthesia and epidural anesthesia had 1 min Apgar score of $\geq 7$, whereas 3/20 (15\%) neonates in GA group had 1 min Apgar score of $\leq 6$.

GA for elective LSCS results in moderate depression of newborn at 1 min (Apgar score 4-6) but 5 min Apgar scores are normal. This suggests that the effect of GA on neonates is transient and there is no significant difference between the effects of general anesthesia and regional anesthesia on Apgar score of neonates at 5 minutes interval, born after full term elective cesarean section of healthy patients. 
Table 3: Induction Delivery / Incision Delivery Interval in group 1, group 2 and group 3.

\begin{tabular}{|l|l|l|l|l|}
\hline I D Interval & SA group & EA group & GA group & Total = n (\%) \\
\hline$<\mathbf{5}$ min & 2 & 1 & 3 & $6(10)$ \\
\hline $\mathbf{5}-\mathbf{1 5}$ min & 14 & 18 & 15 & $47(78)$ \\
\hline$>\mathbf{1 5}$ min & 4 & 1 & 2 & $7(12)$ \\
\hline
\end{tabular}

ID interval was $5-15 \mathrm{~min}$ in $78 \%$ cases. $12 \%$ cases had ID interval of $>15 \mathrm{~min}$ and $10 \%$ cases had ID interval of $<5 \mathrm{~min}$.

Table 4: Relation of Induction- delivery interval to Apgar score at 1 min with different Anesthetic techniques

All neonates with ID interval of 5-15 minutes had 1 min Apgar score of $\geq 7$ irrespective of the anesthetic technique used for elective LSCS. 2 neonates in GA group with ID interval of $<5$ min and 1 neonate in GA group with ID interval of $>15$ min had moderate depression with $1 \mathrm{~min}$ Apgar score of $\leq 6$. ID interval of $<5 \mathrm{~min}$ and $>15 \mathrm{~min}$ is associated with moderate neonatal depression with 1 min Apgar score of 4-6 in neonates born by elective LSCS under GA. ID interval has no effect on Apgar score of neonates in SA and EA group.

Table 5: Relation of Induction -delivery interval to Apgar score at 5 min with different Anesthetic techniques

\begin{tabular}{|c|c|c|c|c|c|c|}
\hline ID Interval & \multicolumn{2}{|c|}{ SA group } & \multicolumn{2}{|c|}{ EA group } & \multicolumn{2}{|c|}{ GA group } \\
\hline & \multicolumn{2}{|c|}{ Apgar score at $1 \mathrm{~min}$} & \multicolumn{2}{|c|}{ Apgar score at $1 \mathrm{~min}$} & \multicolumn{2}{|c|}{ Apgar score at $1 \mathrm{~min}$} \\
\hline & $\geq 7$ & $\leq 6$ & $\geq 7$ & $\leq 6$ & $\geq 7$ & $\leq 6$ \\
\hline$<5$ min & 2 & 0 & 1 & 0 & 1 & 2 \\
\hline $5-15 \mathrm{~min}$ & 14 & 0 & 18 & 0 & 15 & 0 \\
\hline$>15$ min & 4 & 0 & 1 & 0 & 1 & 1 \\
\hline
\end{tabular}

ID interval has no effect on 5 min Apgar score in neonates in group 1, 2 or 3. All neonates had 5 min Apgar score of $\geq 7$.

Table 6: Relation of various anesthetic techniques \& need for resuscitation at birth.

\begin{tabular}{|l|l|l|}
\hline Anesthetic techniques used & No of cases requiring resuscitation at birth & $\%$ \\
\hline Group 1( SA) & $0 / 20$ & 0 \\
\hline Group 2 (EA) & $0 / 20$ & 0 \\
\hline Group 3 (GA) & $3 / 20$ & 15 \\
\hline
\end{tabular}

Total of 3/60 (5\%) newborns required resuscitation at birth. All 3 neonates requiring resuscitation at birth were delivered by LSCS under GA. 2 out of 3 neonates requiring resuscitation had poor respiratory efforts and decreased tone at birth. They were managed by performing initial steps of resuscitation and providing free flow oxygen without IPPV.1 out of 3 neonate requiring resuscitation was managed with initial steps of resuscitation followed by bag and mask ventilation for 30 secs.

Elective LSCS under GA is associated with need for resuscitation at birth, however all neonates requiring resuscitation recovered completely within 1 min of birth. None of the newborns in group 1 and 2 required resuscitation. 
Table 7: Relation of Induction delivery interval to need for resuscitation at birth

\begin{tabular}{|l|l|l|l|}
\hline ID Interval & $\begin{array}{l}\text { No of cases in GA group } \\
\text { requiring resuscitation at } \\
\text { birth }\end{array}$ & $\begin{array}{l}\text { Total no. of cases in GA } \\
\text { group }\end{array}$ & $\%$ \\
\hline$<5 \mathrm{~min}$ & 2 & 3 & 66 \\
\hline $5-15 \mathrm{~min}$ & 0 & 15 & 0 \\
\hline$>15 \mathrm{~min}$ & 1 & 2 & 50 \\
\hline
\end{tabular}

ID interval of $<5$ min and $>15$ min in GA group was associated with need for resuscitation at birth in 2 out of 3 (66\%) cases and 1 out of $2(50 \%)$ cases respectively.

Table 8: Relation of Early neonatal neurobehavioral score at 1 hour to Anesthetic technique used.

\begin{tabular}{|l|l|}
\hline Anesthetic technique used & $\begin{array}{l}\text { Early neonatal neurobehavioral score (ENNS) at 1 } \\
\text { hour (Mean } \pm \text { SD) }\end{array}$ \\
\hline Spinal Anesthesia & $30 \pm 1.3$ \\
\hline Epidural Anesthesia & $28.4 \pm 1.93$ \\
\hline General Anesthesia & $28.3 \pm 1.76$ \\
\hline
\end{tabular}

Early neonatal neurobehavioral score (ENNS score) for all the items i.e. pull to sit, arm recoil, truncal tone, general body tone, rooting reflex, sucking reflex, placing reflex, moro reflex, pin prick, sound and alertness at 1 hour after delivery was comparable in all the three groups $(\mathrm{SA}=30 \pm 1.3, \mathrm{EA}=28.4 \pm 1.93, \mathrm{GA}=28.3 \pm 1.76)$ suggesting that neurobehavioral alterations do not occur after elective LSCS irrespective of the anaesthetic technique used.

\section{Discussion}

Delivery of baby by cesarean section has become increasingly common. However the choice of anaesthetic technique remains controversial. No technique is ideal for cesarean sections and both general and spinal anaesthesia have certain advantages and disadvantages.

The results of our study shows that neonates delivered by elective cesarean section under spinal and epidural anaesthesia have higher mean 1 min Apgar scores as compared to GA group. GA for elective LSCS results in moderate depression of newborn at $1 \mathrm{~min}$ (Apgar score 4-6) but 5 min Apgar scores are normal. This suggests that the effect of GA on neonates is transient and there is no significant difference between the effects of general anesthesia and regional anesthesia on Apgar score of neonates at 5 minutes interval, born after full term elective cesarean section of healthy patients.

Comparisons of the condition of neonates delivered by elective cesarean section under general and spinal anaesthesia have demonstrated better clinical outcomes with regional anesthetic techniques. There are some conflicting results regarding the Apgar scores of babies born to mothers submitted to different anesthesia applications. Similar to our study three studies [6-8] documented the mean Apgar score at 1 min of babies born to mother submitted to EA or GA and reported that scores were significantly lower among babies delivered by mothers submitted to GA. However, Kolatat et al [7] and Kavak et al [9], when comparing spinal with general anesthesia, noted that there was no difference in mean Apgar score at $1 \mathrm{~min}$. A similar trend was noticed with Apgar scores at $5 \mathrm{~min}$ in two studies $[6,8]$ comparing EA with GA, which reported significantly lower scores among babies in the GA group. However, when comparing the Apgar score at $5 \mathrm{~min}$ of babies born to mothers submitted to spinal anesthesia and to GA, Kolatat et al [7] and Kavak et al [9] did not find any differences between groups.

Krishnan et al [10] studied two groups of patients; one received general anesthesia and other spinal anaesthesia and found that no significant difference was seen in the mean 1 minute Apgar scores in the two groups; however more neonates of the general anaesthesia group appeared depressed soon after birth, needing free flow of oxygen and bag and mask ventilation.

Scott W Roberets et al [11] observed that 'although it is widely believed that regional anaesthesia was safer than general anesthesia for the newborn, our results on normal term pregnancies suggested that no anaesthetic method was necessarily hazardous or safer than another and that each method had its own liabilities'. Inhalational agents necessary for general anaesthesia could depress the 
newborn. However similar effects were seen with spinal anesthesia, probably because of the occasionally severe fetal academia.

A study done by Scott W. Roberets [11] and others concluded that there is statistically significant risk of fetal academia of varying severity with the use of regional anaesthesia in women delivered by cesarean without labor. Umbilical artery blood $\mathrm{pH}$ values less than 7.10 were observed in $4 \%$ of fetuses, among whom $1 \%$ had $\mathrm{pH}$ values less than 6.99 .

On the other hand no infant had $\mathrm{pH}$ values less than 7.10 when general anaesthesia was used. They also concluded that the prevalence of low $\mathrm{pH}$ values was significantly increased in those infants exposed to any of regional anesthetic techniques compared to general anaesthesia. Similar results were also documented by Petropoulos G et al [12] who noted that pO2, O2 saturation and umblical artery $\mathrm{pH}$ were higher when GA was administered compared to regional anaesthesia.

In our study it was observed that ID interval of $<5$ min and $>15 \mathrm{~min}$ is associated with moderate neonatal depression with 1 min Apgar score of 4-6 in neonates born by elective LSCS under GA. This may be due to higher degree of fetal acidosis as a result of longer duration of anaesthesia. Patients who receive GA have a relatively higher level of circulating catecholamine's (response evoked by handling the uterus) causing a reduction in placental blood flow thereby leading to acidosis, the effect occurs for prolonged time when ID interval increases

These results can be explained on the basis of anaesthetic agent used. Sodium thiopentone reaches the fetus in seconds and begins to approach equilibrium between maternal circulation, umbilical vein and artery within 23 minutes.

But as the uterine contractions are absent and cord compression less frequent in cesarean section, level of drug increases at the onset of anaesthesia and then falls at a rate determined by redistribution combined with maternal and fetal metabolism and excretion [13]. This results in higher level of barbiturates for shorter induction delivery interval and therefore it has been proposed that ID interval should be $>5 \mathrm{~min}$ [14].

There are different opinions about the ideal time at which the fetus should be delivered after induction of anaesthesia. Many workers have recommended that delivery is best completed $6-8$ minutes after induction of general anaesthesia as nitrous oxide could cause neonatal depression by diffusion through the placenta.

Dutta et al [15] observed that in absence of hypotension there is no change in Apgar scores or acid base status with prolonged induction to delivery interval in spinal anaesthesia.

Morgan et al [16] described that long skin incision-todelivery time more than 8 minutes and uterine-incisionto delivery time more than 180 seconds have been associated with fetal hypoxia and acidosis regardless of the type of anaesthesia.

Regarding early neonatal neurobehavioral score, similar to our study Kolatat et al [7] and Li et al [17] revealed no difference in neurobehavioral score in babies whose mothers received regional and general anaesthesia.

However several studies have reported neurobehavioral changes in neonates in relation to different anaesthetic techniques used. Sener et al [18] documented that neurologic and adaptive capacity scores at 2 and $24 \mathrm{~h}$ were higher in epidural anaesthesia group as compared to general anaesthesia group. Kangas et al noted that neonates delivered by epidural anaesthesia scored lower on rooting at the age of 3 hours.

\section{Conclusion}

Anaesthesia in cesarean section presents a special problem because the anesthetic agents and techniques act on mother as well as on newborn directly or indirectly. There is no technique that acts selectively without side effects on mother and newborn.

Elective LSCS under general anesthesia is associated with need for resuscitation immediately after birth and lower 1 min Apgar scores with moderate depression of neonates. However $5 \mathrm{~min}$ Apgar score and neurobehavioral response of neonate at $1 \mathrm{hr}$ after birth was not significantly different in babies delivered by elective LSCS under general anesthesia.

The effect of general anaesthesia on short term neonatal outcome can be minimized by maintaining an induction delivery interval of 5-15 $\mathrm{min}$.

Elective LSCS under general anesthesia is reasonably safe and has transient effects on newborn with no significant short term outcome if adequate ID interval is maintained and a personnel trained in neonatal resuscitation is available at the time of birth. 
Funding: Nil

Conflict of interest: Nil

Permission from IRB: Yes

\section{References}

1. Wiswell TE, Gannon CM, Jacob J, et al. Delivery room management of the apparently vigorous meconiumstained neonate: results of the multicenter, international collaborative trial. Pediatrics 2000 Jan; 105(1):1-7.

2. Meikle SF, Steiner CA, Zhang J, Lawrence WL. A national estimate of the elective primary cesarean delivery rate. Obstet Gynecol 2005; 105: 751-756.

3. Afolabi BB, Lesi FE, Merah NA. Regional versus general anaesthesia for caesarean section. Cochrane Database Syst Rev 2006 Oct; 18(4):CD004350.

4. Kattwinkel J, Perlman JM, Aziz K, Colby C, Fairchild K, Gallagher J, Hazinski MF, Halamek LP, Kumar P, Little G, McGowan JE, Nightengale B, Ramirez MM, Ringer S, Simon WM, Weiner GM, Wyckoff M, Zaichkin J. Neonatal Resuscitation: 2010 American Heart Association Guidelines for Cardiopulmonary Resuscitation and Emergency Cardiovascular Care. Pediatrics 2010 Nov; 126(5):1400-13.

5. Hughes SC, Levinson G, Rosen MA, Shnider SM. Shnider and Levinson's Anesthesia for Obstetrics. $4^{\text {th }}$ ed.Philadelphia: Lippincott Williams \& Wilkins; 2002.

6. Mancuso A, De Vivo A, Giacobbe A, Priola V, Maggio Savasta L, Guzzo M, De Vivo D. General versus spinal anaesthesia for elective caesarean sections: effects on neonatal short-term outcome. A prospective randomized study. J Matern Fetal Neonatal Med 2010 Oct; 23(10):1114-8.

7. Kolatat T, Somboonnanonda A, Lertakyamanee J, Chinachot T, Tritrakarn T, Muangkasem J. Effects of general and regional anesthesia on the neonate (a prospective, randomized trial). J Med Assoc Thai 1999; 82: 40-45.

8. Yegin A, Ertug Z, Yilmaz M, Erman M. The effects of epidural anesthesia and general anesthesia on newborns at cesarean section. Turk J Med Sci 2003; 33: 311-314.
9. Kavak ZN, Basgul A, Ceyhan N. Short-term outcome of newborn infants: spinal versus general anesthesia for elective cesarean section. A prospective randomized study. Eur J Obstet Gynecol Reprod Biol 2001; 100: 5054.

10. Krishnan L, Gunasekaran N, Bhasaranand N. Anesthesia for Cesarean section and immediate neonatal outcome. Indian J Pediatr 1995 Mar-Apr; 62(2):219-23

11. Roberets SW, Leveno KJ, Sidawi JE, Lucas MJ, Kelly MA. Fetal acidemia associated with regional anaesthesia for elective cesarean delivery. Obstet Gynecol 1995; 85:79-83.

12. Petropoulos G, Siristatidis C, Salamalekis E, Creatsas G. Spinal and epidural versus general anaesthesia for elective cesarean section at term: effect on the acid base status of the mother and newborn. J Matern Fetal Neonatal Med.2003 Apr; 13 (4):260-6

13. Finster M, Mark LC, Morishima HO, Moya F, Perel JM, James LS, Dayton PG. Plasma thiopentone concentration in newborn following delivery under thiopentone - nitrous oxide anaesthesia. Am J Obstet Gynecol 1967 June; 95: 621-29.

14. Kamat SK, Shah MV, Chaudhary LS, Pandya S, Bhatt MM. Effect of induction-delivery and uterine-delivery on Apgar scoring of the newborn. J Postgrad Med. 1991 Jul; $37(3): 125-7$

15. Dutta S, Ostheimer GW, Weiss JB. Neonatal effect of prolonged induction for cesarean section. Obstet Gynecol $1981 ; 58: 331-5$.

16. Morgan GE, Mikhail MS, Murray MJ. Clinical Anaesthesiology. $6^{\text {th }}$ ed. New York: Lange medical books/McGraw Hill Medical Pub division; 2006.

17. Li CH, Zhu CX, He J. Effects of general anesthesia for cesarean section on infants. Zhonghua Fu Chan $\mathrm{Ke} \mathrm{Za}$ Zhi 2006 Mar; 41(3):162-4

18. Sener EB, Guldogus F, Karakaya D, Baris S, Kocamanoglu S, Tur A. Comparison of neonatal effects of epidural and general anesthesia for cesarean section.Gynecol Obstet Invest 2003; 55(1):41-5.

\section{How to cite this article?}

Kosam D, Kosam A, Murthy M. Effect of various techniques of Anesthesia in elective Caesarian section on short term Neonatal outcome. Int J Med Res Rev 2014;2(5):480- 486. doi:10.17511/ijmrr.2014.i05.13 